\title{
ANALISIS ADOPSI LAYANAN INTERNET BANKING OLEH NASABAH PERBANKAN DI PEKANBARU \\ (Technology Acceptance Model)
}

\author{
Eni Noviarni \\ (Dosen Fekonsos UIN Suska Riau - Email : ennynoviarni@yahoo.co.id)
}

\begin{abstract}
This study aims to analyze the factors that affect adoption of internet banking ?rvices by bank customers in the city of Pekanbaru to approach the Technology cceptance Model (TAM). The research method is a survey with descriptive analysis pproach. Data processed and analyzed with statistical models using multiple ?gression help of a computer using SPSS software version 17.

Conclusion of this study indicate that the magnitude of usefulness, ease of use, wareness, risk and social influences affect the adoption of Internet banking by bank ustomers in Pekanbaru.
\end{abstract}

Keywords: TAM, Perceived Usefulness, Perceived Ease of Use, Awareness, erceived of Risk, Sosial Influence, Internet Banking Adoption.

Pendahuluan

Perkembangan teknologi

informasi berbasis sistem, khususnya internet memiliki pengaruh yang besar terhadap proses bisnis di industri perbankan. Sektor perbankan merupakan industri yang memanfaatkan teknologi informasi paling besar karena didasari oleh tingkat kesadaran yang tinggi para pelaku perbankan akan kebutuhan menjalankan bisnis.

Layanan internet banking pertama kali diperkenalkan di Inggris pada tahun 1983, di Amerika Serikat pada tahun 1994 dan tahun 2000 di Jepang. Sedangkan di Indonesia internet banking digunakan pertama kali oleh Bank Papan Sejahtera pada awal dekade 1990-an dan diikuti beberapa bank lainnya. Adopsi teknologi informasi berperan terhadap perubahan interaksi antara perusahaan dengan nasabah. Sebelum diadopsinya teknologi informasi oleh bank, pelayan perbankan hanya bisa dilakukan secara tatap muka dan berinteraksi langsung antara nasabah dengan petugas bank di mana nasabah datang ke bank untuk bertransaksi atau yang dikenal sebagai layanan perbankan konvensional.

Pada saat ini setelah adopsi teknologi informasi oleh perbankan, aktivitas pelayanan nasabah mengarah menjadi pelayanan transaksi berbasis teknologi kearah sistem home banking. Layanan internet banking dapat dilakukan di mana saja dan kapan saja dengan kualitas layanan yang mengandalkan kecepatan, ketepatan, kemudahan, kenyamanan dan harga layanan yang murah dengan cakupan global selama nasabah didukung oleh fasilitas akses internet. Internet banking adalah pemanfaatan teknologi 
internet sebagai media untuk melakukan transaksi yang berhubungan dengan transaksi perbankan dengan menggunakan smartphone, personal notebook, netbook, tablet PC dan komputer sebagai perantara atau penghubung antara nasabah bank dan pihak bank dengan bentuk transaksi yang dilakukan bersifat maya, atau tanpa memerlukan proses tatap muka antara nasabah dan petugas bank yang bersangkutan. Internet banking menjadikan proses pemindahan transaksi perbankan dari yang bersifat konvensional menjadi digital. Menurut Aladwani (2001) internet banking adalah bentuk perbankan online berbasis web perbankan di mana nasabah dapat mengakses langsung rekening ketika mereka menggunakan internet. Transaksi konvensional adalah sebuah transaksi yang memerlukan interaksi secara langsung antara nasabah dan petugas bank. Internet banking menjadi salah satu bentuk alternatif pelayanan terhadap nasabah yang dilakukan melalui web dengan teknologi internet. Perbankan online menjadi sangat diperlukan sebagai bagian dari layanan perbankan moderen.

Adopsi teknologi informasi oleh bank semakin memacu perkembangan industri perbankan. Menurut Ibrahim, dkk (2006) penggunaan teknologi informasi dalam perusahaan jasa akan meningkatkan kualitas pelayanan, mengurangi biaya, dan merupakan standarisasi penawaran dalam pelayanan jasa terhadap konsumen. Speece (2004) mengatakan bahwa pada saat ini telah banyak perusahaan yang berada dalam sektor jasa keuangan secara cepat telah mengimplementasikan kemampuan internet dan layanan elektronik menjadi pilihan layanan yang baik dalam interaksi antara penyedia jasa keuangan dengan nasabah mereka.

Perkembangan teknologi informasi yang sangat pesat dan kemudahan penggunaan teknologi internet yang didukung perkembangan gadget serta semakin terjangkaunya paket internet yang ditawarkan oleh operator seluler, baik dari segi harga maupun jaringan dengan jangkauan yang baik dan luas berdampak positif terhadap peningkatan jumlah pengguna internet di Indonesia. Berdasarkan riset yang dilakukan MarkPlus Insight pengguna internet di Indonesia pada tahun 2010 mencapai 42 juta orang, dan pada tahun 2011 berjumlah 55 juta orang. Pengguna internet di Indonesia pada tahun 2012 mencapai angka 63 juta orang. Sedangkan jumlah pengunjung situs web bank secara online di Indonesia berdasarkan survei yang dilakukan oleh ComScore diketahui bahwa pada tahun 2010 sebesar 435.000 orang, bertambah sebesar $72 \%$ atau 749.000 orang pada tahun 2011 dan berdasarkan survei yang dilakukan oleh Sharing Vision di Indonesia, jumlah pengguna internet banking mencapai 5,7 juta orang pada 2012. Berarti 9 persen pengguna internet di Indonesia adalah pengguna internet banking, dan angkanya diperkirakan bertambah seiring pertumbuhan pengguna internet. Jika dihitung 
berdasarkan nilai transaksi internet banking di Indonesia telah mencapai Rp 3.642 triliun, jumlah tersebut melampaui nilai traksaksi yang dilakukan nasabah melalui ATM + debet yang berada pada Rp 3.476 triliun selama 2012. Pertumbuhan internet bankig pada tahun 2012 mencapai peningkatan 6,6 kali dari jumlah pengguna internet banking pada tahun sebelumnya, tetapi bila dibandingkan dengan jumlah rekening nasabah di perbankan yaitu sebesar 114.650.000 rekening (BPS, 2013), jumlah angka penetrasi adopsi internet banking masih sangat kecil yaitu hanya sebesar $5 \%$.

\section{Rumusan Masalah}

Penyediaan layanan internet banking oleh bank bertujuan untuk memberikan layanan yang lebih baik dengan menawarkan kecepatan, kemudahan, dan layanan sepanjang waktu kepada nasabah. Pertumbuhan penggunaan layanan internet banking oleh nasabah di Indonesia menunjukkan bahwa semakin diterimanya layanan internet banking oleh nasabah. Tetapi jika dilihat dari keseluruhan jumlah nasabah perbankan dengan jumlah nasabah yang menggunakan internet banking angka pertumbuhan penggunaan layanan internet banking masih jauh dari harapan. Penelitian ini akan mengidentifikasikan faktor-faktor yang mempengaruhi penerimaan teknologi internet banking oleh nasabah.

Rumusan masalah dalam penelitian ini, yaitu :
1. Faktor-faktor apakah yang mempengaruhi penerimaan adopsi internet banking oleh nasabah?

2. Bagaimana saran agar internet banking dapat diadopsi secara luas oleh nasabah perbankan?

Agar sasaran penelitian dapat tercapai, maka dilakukan pembatasan masalah pada penelitian ini, yaitu :

1. Responden penelitian adalah nasabah bank yang berdomisili di kota Pekanbaru yang pernah menggunakan dan memiliki keinginan untuk menggunakan kembali internet banking.

2. Internet banking yang dimaksud dalam penelitian adalah layanan perbankan melalui website di mana nasabah dapat mengakses rekening mereka ketika terkoneksi dengan jaringan internet.

\section{Tujuan Penelitian}

Penelitian ini bertujuan untuk menganalisis persepsi adopsi internet banking oleh nasabah perbankan, dengan mengidentifikasi lima faktor yang dirasakan nasabah perbankan, yaitu :

1. Persepsi kegunaan (perceived usefulness, $P U$ ), yaitu keadaan di mana seseorang percaya bahwa dengan menggunakan teknologi tertentu dapat meningkatkan kinerjanya (Davis, 1989).

2. Persepsi kemudahan dalam menggunakan (perceived ease of use, PEOU), yaitu keadaan di mana seseorang percaya bahwa penggunaan teknologi informasi merupakan hal yang mudah dan tidak memerlukan usaha keras dari penggunanya (Davis, 1989). 
3. Kesadaran konsumen (consumer awareness) yaitu suatu keadaan di mana seseorang yang merasa, tahu, ingat atau mengerti akan produk atau jasa. Adopsi atau penolakan dimulai ketika konsumen sadar terhadap produk. Konsumen akan melalui proses pengetahuan, persuasi, keputusan dan konfirmasi sebelum mereka siap untuk mengadosi suatu produk atau jasa (Sathye,1999). Konsumen akan mencari produk dan perbankan yang dapat menawarkan nilai terbaik bagi mereka. Sathye (1999) yang melakukan penelitian pada konsumen di Australia menemukan bahwa konsumen menyadari tentang keuntungan atau kerugian yang terkait dengan penggunaan layanan perbankan secara online.

4. Resiko yang dirasakan (perceived of risk, POR), menurut Povlou (2002) resiko mengacu pada keseluruhan ketidakpastian yang dirasakan dalam situasi pembelian tertentu. Persepsi resiko adalah suatu keadaaan adanya ketidakpastian yang transaksi online karena infrastruktur teknologi internet yang terbuka. Resiko yang dihadapi nasabah berkaitan dengan keamanan dan kerahasian. Penelitian yang dilakukan oleh Polatoglu dan Ekin (2001) menemukan bahwa resiko merupakan salah satu faktor utama yang mempengaruhi adopsi internet banking.
5. Pengaruh sosial (Social influence), yaitu pengaruh dari lingkungan yang dapat menyebabkan seseorang menggunakan suatu teknologi. Pengaruh sosial merujuk pada perubahan sikap atau perilaku sebagai hasil interaksi atau pengaruh pihak lain. Faktor pengaruh sosial dapat dilihat dari hubungan pertemanan, keluarga dan orang tua dalam mempengaruhi keputusan pembelian. Beberapa hasil penelitian menunjukkan bahwa pengaruh sosial berpengaruh pada keputusan pembelian. Variabel pengaruh sosial diukur melalui keberadaan teman, anggota keluarga dan orang tua dalam mempengaruhi keputusan memilih produk (Arangga, 2000).

6. Adopsi, adopsi merujuk pada proses penerimaan sesuatu yang baru (inovasi) yaitu menerima sesuatu yang ditawarkan dan diupayakan oleh pihak lain. Dengan penerimaan yang mengandung arti benar-benar melaksanakan atau terus menggunakan layanan, produk atau ide. Adopsi atau penolakan inovasi dimulai ketika konsumen sadar pada produk (Sathye, 1999; Rogers dan Shoemaker, 1971).

\section{Internet Banking}

Internet banking merupakan bagian dari layanan perbankan elektronik atau e-banking. E-banking adalah layanan perbankan yang memanfaatkan teknologi informasi dan komunikasi. Produk-produk electronic banking berupa ATM, kartu kredit, 
kartu debet, internet banking, SMS/mobile banking dan phone banking. E-banking memberikan layanan perbankan menjadi relatif tidak terbatas, baik dari sisi waktu maupun dari sisi jangkauan geografis sehingga berdampak positif meningkatkan volume dan nilai nominal transaksi keuangan di perbankan. Menurut Budi Raharjo (2001) dalam Ratih (2009) manfaat bagi bank yang menyediakan layanan internet banking adalah sebagai :

1. Business Expansion. Sebelumnya bank harus memiliki sebuah kantor cabang untuk beroperasi di tempat tertentu yang tentunya membutuhkan dana yang cukup besar. Dengan layanan internet banking bank dapat melayani nasabah mereka tanpa menggunakan kantor dan karyawan.

2. Customer Loyality. Nasabah, khususnya yang sering bergerak (mobile), dapat menggunakan satu layanan bank saja, karena layanan internet banking dapat berhubungan diantara bank-bank yang memilki layanan yang sama sehingga nasabah akan merasa lebih nyaman untuk melakukan aktivitas perbankannya tanpa harus membuka account di bank lain.

3. Revenue and Cost Improvement. Biaya yang dikeluarkan untuk memberikan layanan perbankan melalui internet banking lebih murah dari pada membuka kantor cabang.
4. Competitive Advantage. Bank yang memiliki layanan internet banking akan memiliki keuntungan dibandingkan dengan bank yang tidak memiliki internet banking. Masyarakat akan lebih memilih membuka account di bank yang memiliki fasilitas internet banking.

5. New Business Model. Internet banking mendorong pertumbuhan bisnis melalui web dengan cepat.

Keberhasilan adopsi internet banking tergantung dari bagaimana nasabah menerima sistem tersebut. Menjadi sangat penting pihak bank untuk mengetahui bagaimana nasabah mengapresiasi internet banking sehingga bank dapat meningkatkan layanan dan mengembangkan kebijakan strategis agar nasabah melakukan adopsi internet banking.

\section{Metode Penelitian}

Model hipotesis pada penelitian ini menggunakan model TAM (Technology Acceptance Model) yang menggunakan pendekatan psikologis yang mengukur faktor-faktor yang dapat mempengaruhi seseorang dalam penerimaan individu terhadap suatu teknologi. TAM diperkenalkan pertama kali oleh Fred Davis pada tahun 1986. Menurut Davis (1986) TAM adalah salah satu model perilaku dalam pemanfaatan teknologi informasi dalam literatur sistem informasi manajemen. TAM bertujuan untuk menjelaskan dan memperkirakan penerimaan (acceptance) pengguna terhadap suatu sistem informasi. TAM menyediakan dasar teoritis untuk mengetahui faktor- 
faktor yang mempengaruhi penerimaan terhadap suatu teknologi dalam suatu organisasi. TAM menjelaskan hubungan sebab akibat antara perilaku dan keyakinan (manfaat suatu sistem informasi dan kemudahan penggunaan), tujuan, serta penggunaan aktual dari pengguna sistem informasi. Manfaat yang dirasakan oleh pengguna sistem informasi adalah sejauh mana seseorang percaya bahwa penggunaan sistem tertentu akan meningkatkan kinerja dan kemudahan yang dirasakan dalam penggunaan sistem informasi. TAM telah diakui secara umum sebagai model yang digunakan untuk memprediksi penerimaan individu terhadap teknologi baru (Doll dkk, 1998).

Persepsi kemudahan penggunaan dan kegunaan adalah faktor penting yang mempengaruhi penerimaan individu terhadap sistem informasi atau teknologi baru. Beberapa penelitian sebelumnya menemukan bahwa terdapat hubungan positif antara persepsi kemudahan penggunaan dan kegunaan yang dirasakan sebagai faktor penting dalam penggunaan e-banking (Poon, 2008; Johnson dan Marakas, 2000; Davis dan Venkatesh, 1996). Model yang digunakan dalam penelitan ini berdasarkan model TAM adalah sebagai berikut :

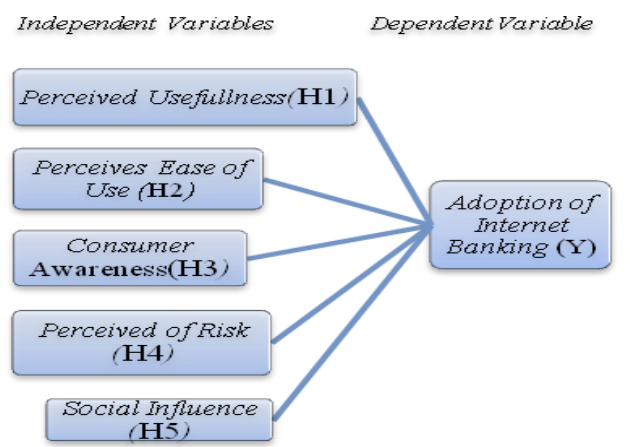

Dengan menerapkan model TAM, beberapa hipotesis yang akan diuji dalam penelitian ini adalah :

Hipotesis 1

H0: Perceived Usefulness (PU) tidak berpengaruh secara signifikan terhadap adopsi internet banking.

H1: Perceived Usefulness (PU) berpengaruh secara signifikan terhadap adopsi internet banking.

Hipotesis 2

H0: Perceived Eease of Use (PEOU) tidak berpengaruh secara signifikan terhadap adopsi internet banking.

H1: $\quad$ Perceived Ease of Use, PEOU) berpengaruh secara signifikan terhadap adopsi internet banking.

Hipotesis 3

H0: Consumer Awareness tidak berpengaruh secara signifikan terhadap adopsi internet banking.

H1: Consumer Awareness berpengaruh secara signifikan terhadap adopsi internet banking.

Hipotesis 4

H0: Perceived of risk, POR tidak berpengaruh secara signifikan terhadap adopsi internet banking.

H1: Perceived of risk, POR berpengaruh secara signifikan 
terhadap adopsi internet banking.

Hipotesis 5

H0: Social Influence tidak berpengaruh secara signifikan terhadap adopsi internet banking.

H1: Social Influence berpengaruh secara signifikan terhadap adopsi internet banking.

Variabel penelitian diukur melalui indikator sebagai berikut :

1. Perceived Usefulness, digunakan dan diukur melalui indikator:

a. Kecepatan transaksi

b. Kegunaan internet banking

c. Efektivitas transaksi

d. Mendukung aktivitas

2. Perceived ease of use, diukur melalui indikator :
a. Efisiensi waktu
b. Kemampuan melakukan transaksi
c. Kemudahan operasional internet banking
d. Penggunaan yang fleksibel

3. Consumer awareness, diukur melalui indikator :
a. Mengenal dan mengingat internet banking
b. Mengerti tentang layanan internet banking
c. Suka menggunakan internet banking
d. Memilih internet banking dibanding kan layanan lain

4. Perceived risk, diukur melalui indikator :
a. Besarnya resiko
b. Keamanan transaksi
c. Kebutuhan transaksi
d. Jaminan keamanan dari bank

5. Social influence, diukur melalui indikator:
a. keberadaan teman
b. keberadaan anggota keluarga
c. keberadaan orang tua atau yang dituakan

6. Adopsi internet banking diukur melalui indikator yaitu:
a. Keinginan menggunakan internet banking di masa yang akan datang
b. Kesesuaian penggunaan internet banking dengan kebutuhan
c. Dukungan dalam menggunakan internet banking
d. Keinginan merekomendasikan internet banking
Setelah ditentukan model penelitian maka disusun kuesioner yang pertanyaannya diadaptasi dan dilakukan pengembangan dari penelitian sebelumnya berdasarkan model dan tujuan dari penelitian. Jawaban responden pada kuesioner penelitian disusun menggunakan skala Likert dengan lima tingkat skala. Untuk menguji validitas alat ukur yang digunakan dalam penelitian maka dilakukan uji validas terhadap pertanyaan yang telah diisi oleh responden sehingga dapat diketahui apakah pertanyaan dalam kuesioner dapat dimengerti dan menghasilkan jawaban yang konsisten jika ditanyakan secara berulang-ulang pada responden yang sama. Untuk mengetahui apakah kuesioner cukup handal dan dapat dipercaya dilakukan uji reliabilitas. Jika hasil pengujian 
menunjukkan data tidak valid dan tidak reliabel, maka dilakukan kembali penyusunan pertanyaan kuesioner dan pengambilan data. Data yang digunakan dalam penelitian ini didapat dengan menyebarkan kuesioner penelitian kepada 100 responden yang merupakan sampel dalam penelitian. Menurut Sugiyono (2005:44) sampel adalah bagian dari jumlah dan karakteristik yang dimiliki oleh populasi. Populasi merupakan seluruh subyek penelitian. Populasi menurut Singarimbun (1989:8) adalah jumlah keseluruhan dari unit-unit analisis yang memiliki ciri-ciri yang akan diduga. Metode pengambilan sampel menggunakan purposive sampling. Purposive sampling adalah metode pengambilan sampel berdasarkan penilaian subyektif peneliti berdasarkan pada karakteristik tertentu yang dianggap mempunyai kaitan dengan karakteristik populasi yang sudah diketahui sebelumnya dengan pertimbangan tertentu. Data yang digunakan dalam penelitian ini adalah data primer dan pengumpulan data dilakukan menggunakan kuesioner secara langsung. Data primer adalah data atau segala informasi yang diperoleh dan didapat peneliti langsung dari sumber pertama.

Pengolahan dan analisa data yang telah didapat dari penyebaran kuesioner yang telah diisi oleh responden dilakukan dengan menggunakan model statistik regresi berganda dengan bantuan komputer menggunakan perangkat lunak SPSS Versi 17.

\section{Pengolahan Data dan Analisis}

Data yang didapat berasal dari responden yang mengisi kuesioner yang disebarkan peneliti. Kriteria sampel yang diambil dalam penelitian adalah nasabah bank yang bertempat tinggal di Pekanbaru yang telah mengadopsi internet banking dan mau berpartisipasi dalam pengisian kuesioner.

Tabel 1.

Profil Responden

\begin{tabular}{|l|l|c|l|}
\hline Demografi & \multicolumn{1}{|c|}{ Item } & Jumlah & \multicolumn{1}{c|}{$\%$} \\
\hline Jenis & Pria & 62 & $62 \%$ \\
kelamin & Wanita & 38 & $38 \%$ \\
\hline Kelompok & $<20$ tahun & 18 & $18 \%$ \\
umur & $21-30$ tahun & 20 & $20 \%$ \\
& $31-40$ tahun & 31 & $31 \%$ \\
& $41-50$ tahun & 25 & $25 \%$ \\
& $>50$ tahun & 06 & $6 \%$ \\
\hline Pendidikan & SMP & 10 & $10 \%$ \\
& SMU & 32 & $32 \%$ \\
& D3/Sarjana & 53 & $53 \%$ \\
& Lainnya & 05 & $5 \%$ \\
\hline Pekerjaan & Pelajar/ & 21 & $21 \%$ \\
& Mahasiswa & & \\
& ABRI/POLRI & 16 & $16 \%$ \\
& /PNS & & \\
& Wiraswasta & 32 & $32 \%$ \\
& Karyawan & 20 & $20 \%$ \\
& Swasta & & \\
& Lainnya & 11 & $11 \%$ \\
\hline
\end{tabular}

Sumber : data primer yang diolah, 2013

Jumlah responden $=100$ orang

Dari data di atas diketahui bahwa jumlah responden pria lebih banyak dari wanita, jumlah kelompok umur yang terbanyak berada pada kisaran 31-40 tahun sebesar $31 \%$ diikuti kelompok umur 41-50 tahun sebesar $25 \%$, hal ini menunjukkan adposi internet banking mayoritas oleh kelompok umur produktif. Dilihat dari jenjang pendidikan responden didominasi pada pendidikan 
D3/Sarjana yaitu sebesar 53\%, dan responden terbesar jika dilihat dari pekerjaan berasal dari wiraswasta sebesar 32\%, menunjukkan layanan internet banking digunakan dalam aktivitas mereka.

\section{Hasil Uji Kualitas Data}

Uji kualitas data meliputi uji validitas dan uji reliabilitas. Pengujian validitas dan reliabilitas dilakukan dengan bantuan komputer menggunakan perangkat lunak SPSS for Windows Versi 17. Pada uji validitas butir pertanyaan pada kuesioner yang dinyatakan valid harus memenuhi syarat nilai korelasi butir (satu pertanyaan) dengan total butir di atas 0,2 (Sufren,2013). Kriteria untuk menyatakan kehandalan pertanyaan pada kuesioner dinyatakan realibel jika nilai koefisien Cronbach's Alpha berada diatas nilai 0,6 .

Tabel 2.

Hasil uji validitas dan reabilitas

\begin{tabular}{|c|c|c|c|c|}
\hline \multirow{2}{*}{ Variabel } & \multirow{2}{*}{ Item } & \multicolumn{2}{|c|}{ Nilai } & \multirow{2}{*}{$\begin{array}{c}\text { Keputus } \\
\text { an }\end{array}$} \\
\hline & & $\begin{array}{c}\text { Validi } \\
\text { tas }\end{array}$ & $\begin{array}{c}\text { Realibel } \\
\text { (alpha) }\end{array}$ & \\
\hline Kegunaan & $\mathrm{X} 1 \mathrm{p}_{1-4}$ & $\begin{array}{c}0,423- \\
0,728\end{array}$ & 0,785 & $\begin{array}{c}\text { valid } \\
\text { realibel }\end{array}$ \\
\hline Kemudahan & $\mathrm{X} 2 \mathrm{p}_{1-4}$ & $\begin{array}{l}0,326- \\
0,730\end{array}$ & 0,765 & $\begin{array}{c}\text { Valid } \\
\text { realibel }\end{array}$ \\
\hline Kesadaran & $\mathrm{X} 3 \mathrm{p}_{1-4}$ & $\begin{array}{l}0,635- \\
0,733\end{array}$ & 0,850 & $\begin{array}{c}\text { Valid } \\
\text { realibel }\end{array}$ \\
\hline Resiko & $\mathrm{X} 4 \mathrm{p}_{1-4}$ & $\begin{array}{l}0,680- \\
0,777\end{array}$ & 0,871 & $\begin{array}{c}\text { Valid } \\
\text { realibel }\end{array}$ \\
\hline $\begin{array}{l}\text { Pengaruh } \\
\text { sosial }\end{array}$ & $X 5 p_{1-3}$ & $\begin{array}{l}0,622- \\
0,646 \\
\end{array}$ & 0,668 & $\begin{array}{c}\text { Valid } \\
\text { realibel }\end{array}$ \\
\hline Adopsi & $\mathrm{Yp}_{1-4}$ & $\begin{array}{l}0,359- \\
0,716\end{array}$ & 0,787 & $\begin{array}{c}\text { Valid } \\
\text { realibel }\end{array}$ \\
\hline
\end{tabular}

Sumber : data primer yang diolah, 2013

Berdasarkan Tabel 2 di atas maka dapat dilihat bahwa seluruh pertanyaan pada kuesioner dinyatakan valid dan realibel.

\section{Uji Regresi}

Besarnya pengaruh variabel independent (kegunaan, kemudahan dalam penggunaan, kesadaran resiko dan pengaruh sosial ) dengan variabel dependent (adopsi internet banking) secara bersama-sama dapat dihitung melalui persamaan regresi berganda.

Berdasarkan perhitungan melalui komputer dengan menggunakan perangkat lunak SPSS 17 diperoleh hasil regresi sebagai berikut :

Tabel 3.

Tabel Coefficient Hasil Analisis

$$
\text { Regresi }
$$

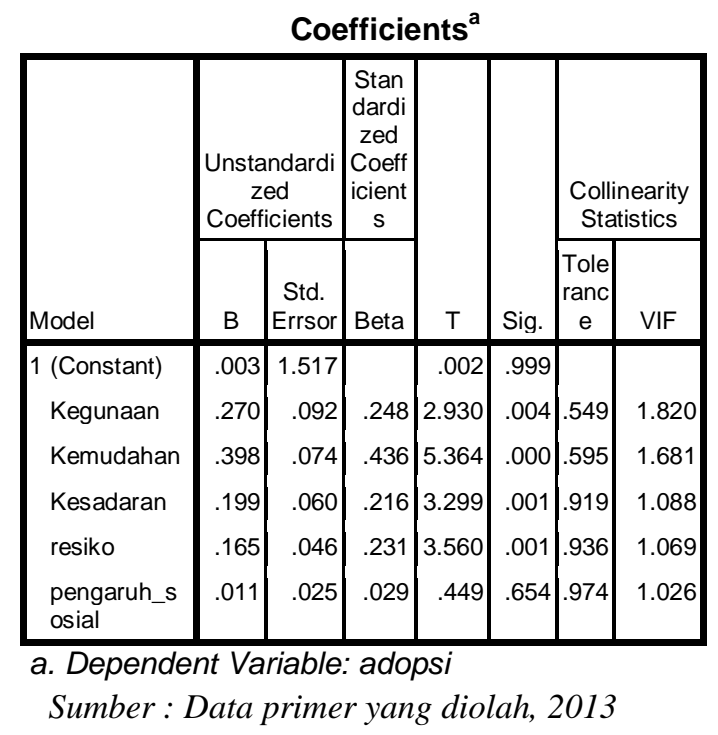

Berdasarkan tabel 3 diatas, maka persamaan regresi yang terbentuk pada uji regresi ini adalah :

$\mathrm{Y}=0,248 \mathrm{X}_{1}+0,436 \mathrm{X}_{2}+0,216 \mathrm{X}_{3}+$ $0,231 \mathrm{X}_{4}+0,039 \mathrm{X}_{5}$

Keterangan :

$\mathrm{X}_{1}=$ Persepsi kegunaan

$\mathrm{X}_{2}=$ Kemudahan dalam penggunaan

$\mathrm{X}_{3}=$ Kesadaran 
$\mathrm{X}_{4}=$ Resiko

$\mathrm{X}_{5}=$ Pengaruh Sosial

$\mathrm{Y}=$ Adopsi Internet banking

Berdasarkan persamaan dapat diketahui bahwa variabel bebas yang paling berpengaruh adalah variabel kemudahan dalam penggunaan dengan koefisien 0,436, diikuti oleh variabel kegunaan dengan koefisien 0,248, variabel resiko dengan koefisien 0,231, variabel kesadaran dengan koefisien 0,216. Sedangkan variabel yang berpengaruh paling rendah adalah variabel pengaruh sosial dengan koefisien 0,039. Dari persamaan tersebut dapat terlihat bahwa keseluruhan variabel bebas (kegunaan, kemudahan dalam penggunaan, kesadaran, resiko dan pengaruh sosial) berpengaruh positif terhadap adopsi nasabah menggunakan internet banking.

Tabel 4.

Hasil Perhitungan Nilai Koefisien Determinasi $\left(\mathrm{R}_{2}\right)$

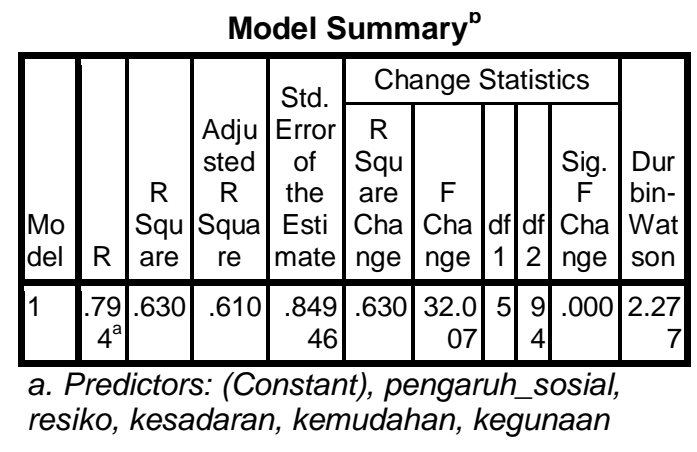

b. Dependent Variable: adopsi internet banking Sumber : Data primer yang diolah, 2013

Dari hasil perhitungan, menunjukkan bahwa nilai koefisien korelasi berganda (R) adalah sebesar 0,794, artinya angka tersebut menunjukkan hubungan antara variabel dependen yaitu adopsi internet banking dengan variabel independen yaitu kegunaan, kemudahan dalam penggunaan, kesadaran, resiko dan pengaruh sosial adalah erat dan positif karena semakin mendekati angka satu (1). Sedangkan hasil perhitungan nilai koefisien determinasi ( $\left.\mathrm{R}_{2}\right)$ berdasarkan hasil perhitungan estimasi regresi, diperoleh nilai koefisien determinasi yang disesuaikan (adjusted $R^{2}$ ) adalah 0,61 artinya 61 persen variasi dari semua variabel bebas (kegunaan, kemudahan dalam penggunaan, kesadaran, resiko dan pengaruh sosial) dapat menerangkan variabel tak bebas (adopsi internet banking), sedangkan sisanya sebesar 39 persen diterangkan oleh variabel lain yang tidak diajukan dalam penelitian ini.

Hasil pengujian koefisien regresi untuk menguji signifikansi hubungan antara variabel independen (X) dan variabel dependen (Y) baik secara bersama-sama (dengan Uji F) maupun secara individual (dengan Uji t) dapat diketahui sebagai berikut :

\section{Uji t (t-test)}

Uji $t$ (t-test) ini dimaksudkan untuk mengetahui pengaruh secara parsial (individu) variabel-variabel independen (kegunaan, kemudahan dalam penggunaan, kesadaran, resiko dan pengaruh sosial ) terhadap variabel dependen (adosi internet banking) atau menguji signifikansi konstanta dan variabel dependen. Hasil perhitungan uji t dapat dilihat di tabel 3 diatas.

1. Dari hasil perhitungan didapat nilai $t$ hitung sebesar 2,930 dengan tingkat 
signifikansi sebesar 0,004. Apabila dilihat dari nilai signifikansi yang kurang dari 0,05 maka dapat disimpulkan $\mathrm{H} 1$ diterima, artinya bahwa ada pengaruh variabel kegunaan terhadap adopsi internet banking.

2. Dari hasil perhitungan di dapat nilai t hitung sebesar 5,364 dengan tingkat signifikansi sebesar 0,000. Apabila dilihat dari nilai signifikansi yang kurang dari 0,05 maka dapat disimpulkan $\mathrm{H} 2$ diterima, artinya bahwa ada pengaruh yang sangat berarti variabel kemudahan dalam penggunaan terhadap adopsi internet banking.

3. Dari hasil perhitungan didapat nilai t hitung sebesar 3,299 dengan tingkat signifikansi sebesar 0,001. Apabila dilihat dari nilai signifikansi yang kurang dari 0,05 maka dapat disimpulkan $\mathrm{H} 3$ diterima, artinya bahwa ada pengaruh yang sangat berarti variabel kesadaran terhadap adopsi internet banking .

4. Dari hasil perhitungan didapat nilai t hitung sebesar 3,56 dengan tingkat signifikansi sebesar 0,001. Apabila dilihat dari nilai signifikansi yang kurang dari 0,05 maka dapat disimpulkan $\mathrm{H} 4$ diterima, artinya bahwa ada pengaruh yang sangat berarti variabel resiko terhadap adopsi internet banking .

\section{Uji F (F-test)}

Uji F (F-test) dimaksudkan untuk mengetahui pengaruh variabel independen (kegunaan, kemudahan dalam penggunaan, kesadaran, resiko dan pengaruh sosial) secara simultan (bersama-sama) terhadap variabel tak bebas (adposi internet banking ). Hasil perhitungan uji $\mathrm{F}$ adalah sebagai berikut :

Tabel 5.

Hasil Perhitungan Uji F

ANOVA $^{\circ}$

\begin{tabular}{|l|r|r|r|r|l|}
\hline Model & $\begin{array}{c}\text { Sum of } \\
\text { Squares }\end{array}$ & Df & $\begin{array}{c}\text { Mean } \\
\text { Square }\end{array}$ & F & Sig. \\
\hline 1 Regression & 115.481 & 5 & 23.096 & 32.007 & $.000^{\text {a }}$ \\
Residual & 67.829 & 94 & .722 & & \\
Total & 183.310 & 99 & & & \\
\hline
\end{tabular}
a. Predictors: (Constant), pengaruh_sosial,
resiko, kesadaran, kemudahan, kegunaan
b. Dependent Variable: adopsi

Dari hasil perhitungan didapat nilai $\mathrm{F}$ hitung sebesar 32,007 dengan probabilitas signifikansi mendekati nol $(\mathrm{P}$ value $=0,000)$, dengan demikian Ho ditolak, artinya bahwa variabel kegunaan, kemudahan dalam penggunaan, kesadaran, resiko dan pengaruh sosial secara bersama-sama mempunyai pengaruh yang berarti pada adopsi nasabah terhadap internet banking.

\section{Kesimpulan}

Kesimpulan yang dapat diambil dari penelitian adalah, bahwa adopsi nasabah terhadap internet banking di Pekanbaru adalah sebagai berikut :

1. Adopsi internet banking oleh nasabah di kota Pekanbaru terutama dipengaruhi oleh kemudahan dalam penggunaan, dan akan terus menggunakan jika mereka terus mendapatkan kemudahan dalam bertransaksi 
dengan menggunakan layanan perbankan internet banking.

2. Nasabah mengadosi internet banking karena menganggap dengan menggunakan layanan internet banking akan memberikan manfaat pada dirinya dalam melakukan transaksi.

3. Semakin bertumbuhnya kesadaran nasabah pada layanan internet banking akan meningkatkan adopsi internet banking di kota Pekanbaru.

4. Resiko yang dihadapi oleh nasabah dalam adopsi internet banking menjadi salah satu faktor penentu bagi nasabah dalam adopsi internet banking.

5. Pengaruh sosial dari lingkungan seperti pengaruh dan ajakan dari teman, keluarga, dan orang tua atau orang yang dituakan akan memberikan dorongan adopsi internet banking oleh nasabah bank di Pekanbaru.

\section{Saran}

Berdasarkan kesimpulan penelitian, dapat disusun beberapa saran untuk memperbaiki dan meningkatkan tingkat adopsi internet banking pada nasabah perbankan. Saran-saran tersebut adalah sebagai berikut :

1. Berdasarkan pengaruh dari faktor kegunaan yang mempengaruhi nasabah mengadopsi internet banking, pihak bank mempertahankan dan meningkatkan kegunaan sehingga memberikan nilai lebih dan manfaat bagi nasabah yang mengadopsi internet banking.

2. Pihak bank lebih memberikan pemahaman pada penggunaan layanan internet banking sehingga nasabah nyaman dan mudah dalam adopsi internet banking.

3. Bank menumbuhkan dan meningkatkan kesadaran nasabah dalam adopsi internet banking sehingga lebih meningkatkan jumlah nasabah di Pekanbaru yang mengadopsi internet banking.

4. Pemahaman resiko adopsi internet banking oleh nasabah dan perlindungan dan antisipasi resiko layanan internet banking oleh pihak bank akan meningkatkan rasa aman dan percaya nasabah dalam adopsi internet banking.

\section{Daftar Pustaka}

(2011), Pengguna Internet Banking Melonjak di Asia Tenggara,(http://www.antaranew s.com).

(2012), Pengguna Online Banking Indonesia Terbanyak di Asia Tenggara, (http://www.merdeka.com).

(2013), Pertumbuhan Internet Banking dan $e$ Commerce di Indonesia, (http://www.sharingvision.com). (2013), Pengguna Baru Internet,(http://www.teknologi.k ompasiana.com).

Davis, F.D,1989. Perceived usefulness, perceived ease of use, and user acceptance of information 
technology. MS Quarterly (online), Vol. 13 Iss. 3, pg. 318. http://www.cba.hawaii.edu/chis mar/ITM704/DavisTAM 1989.pdf.

Davis, F.D, Bagozzi, R.P, and Warshaw, P.R, 1989. User acceptance of computer technology: A comparison of two theoretical models.Management Science (online), Vol. 35 Iss. 8, pg. 982.http://home.hia.no/fwahid01 /thesis/articles/Davis/1989).pdf.

Doll, WJ, Henddrickson, A and Deng, 1998.Using Davis's Perceived Usefulness and Ease of Use Instruments for Decision Making: A Confirmation and Multi-Group Invariance Analysis. Decision Science, Vol.29, No.4, Pp.839-869.

Ibrahim, EE, Joseph, $M$ and Ibeh, KIN,2006. Customers' perception of electronic service delivery in the UK retail banking sector. International Journal of Bank Marketing, Vol. 24, No. 7, pp. 475-493

Pavlou,PA,2003.Consumer acceptance of electronic commerce: Integrating trust and risk with the Technology Acceptance Model. International Journal of Electronic Commerce, Vol.7, No. 3, Pp. 101-134.

Pavlou, Fred, 2001), "Perceived Usefulnes, Perceived Ease of Use and User Acceptance of Information Technology", MIS Quarterly, September.
Poon, WC, 2008. Users' adoption of ebanking services: the Malaysian perspective. Journal of Business \& Industrial Marketing, Vol. 23, No.1, Pp. 59-69.

Rahmath Safeena,2010. Customer Perspectives on E-business Value: Case Study on Internet Banking, Journal of Internet Banking and Commerce, April 2010, vol. 15, no.1. (http://www.arraydev.com/comm erce/jibc/).

Ratih Wijayanti, 2009, Analisis Technology Acceptance Model (Tam) terhadap Faktor-Faktor yang Mempengaruhi Penerimaan Nasabah Terhadap Layanan Internet Banking, Jurusan Akuntansi, Fakultas Ekonomi Universitas Gunadarma. Jakarta.

Rotchanakitumnuai, S and Speece, $\mathrm{M}$. 2004. Corporate Customer Perspectives on Business Value of Thai Internet Banking. Journal of Electronic Commerce Research, Vol. 5, No.4, pp.270286.

Santoso, Singgih, 2003.Mengolah Data Statistik secara Profesional, Elex Media Komputindo, Jakarta.

Sathye, M, 1999.Adoption of Internet banking by Australian consumers: an empirical investigation. International Journal of Bank Marketing, Vol. 17, No. 7, pp: 324-334.

Sufren, 2013. Mahir Menggunakan SPSS secara Otodidak. Elex Media Komputindo, Jakarta. 
JURNAL AL-IQTISHAD, EDISI : 10 VOL. I TAHUN 2014

Sugiyono, 2009. Metode Penelitian Pendidikan : Pendekatan Kuatitatif, Kualitatif dan $R \& D$. Alfabeta, Bandung.

Sutrisno Hadi, 1994. Analisa Regresi. Andi Offset, Jakarta. 